\title{
New Era for Schools and Programs of Public Health in Canada
}

\author{
Richard Massé MD, MSc, FRCPC, ${ }^{1}$ \\ Brent Moloughney MD, MSc, FRCPC ${ }^{2}$
}

\begin{abstract}
In Canada, in the last few years, there has been a very rapid expansion of programs and schools of public health in response to several crises or emergency situations. Provincial and national investigations convened after the Severe Acute Respiratory Syndrome outbreak in Toronto in 2003 underlined important deficiencies in the institutional capacity of the public health system and the need to develop training of public health professionals and managers on a large scale.
\end{abstract}

Key Words: Canadian Schools of Public Health, master of public health, public health training

Recommended Citation: Massé R, Moloughney B. New Era for Schools of Public Health in Canada. Public Health Reviews. 2011;33:277-88.

\section{INTRODUCTION}

From about five programs in the 1990's, there will be in September 2011, 15 Canadian universities offering MPH or MPH-type degrees in public health and as many as 500 new graduates who receive their master's degree annually. Ten years ago, there were no schools of public health, and now there are seven developed or rapidly emerging, although thus far only one is in the process of being accredited by an independent, internationally recognized body. Most universities are exclusively targeting graduate level training, including e-learning and continuous professional development, as an integral part of their curriculum, but there are at least three that offer undergraduate programs.

\footnotetext{
${ }^{1}$ University of Montreal, Faculty of Medicine, School of Public Health.

${ }^{2}$ University of Toronto, Dalla Lana School of Public Health.
}

Corresponding Author Contact Information: Richard Massé at richard.masse @ umontreal. ca; Pavillon Mont-Royal, Université de Montréal. C.P. 6128, succursale Centre-ville, Montréal (QC) Canada H3C 3J7. 
The involvement of more than 20 different academic institutions has resulted in a strong interest to create a network of programs and schools of public health in Canada. Initial priorities of this new network will be to improve the quality of the programs including development and refinement of core competencies, facilitate communication and collaboration between the members and, finally, promote public health training, research and capacity building activities. Greater collaboration may also lead to higher standards, reduced duplication and greater efficiency of efforts. To date, no clear quantitative ascertainment of our public health workforce's needs has been done.

\section{CHANGING CONTEXT FOR PUBLIC HEALTH TRAINING IN CANADA}

Up until the early 1970's, only two schools of public health (SPHs), or hygiene as they were called then, existed in Canada: one at the University of Toronto (1927-1975) and the other at the University of Montréal (19451975). ${ }^{1-3}$ They were both closed thereafter for different reasons and integrated within their respective faculty of medicine. There were also limited options for graduate training in public health. In the mid 1970s, the specialty of Community Medicine was recognized by the Royal College of Physicians but some of the new trainees had to pursue their academic training in the basic public health sciences in other centres such as in the United States or overseas.

The 1974 Lalonde Report (New Perspective on the Health of Canadians), and the 1986 Ottawa Charter for Health Promotion were landmark documents emphasizing the importance of the broad determinants of health, including medical services, and the necessity to go beyond the previously dominant biomedical focus. ${ }^{4,5}$ The vision of a "new public health', more socially and politically oriented, was coming forward. ${ }^{6}$ This later orientation was recently reinforced in 2008 by the WHO Report on the Social Determinants of Health led by Sir Michael Marmot and a team of commissioners from around the globe, including Canada. ${ }^{7}$

Early in the $21^{\text {st }}$ century, Canada experienced some significant public health emergencies, first with the $E$. coli epidemic in Walkerton, Ontario, in May 2000, and then the Cryptosporidium contamination in North Battleford, Saskatchewan, during the spring of 2001, showing deficiencies in the safety of drinking water and the lack of protective measures in place for the population. ${ }^{8,9}$ Following the 9/11 tragedy in 2001 and the anthrax crisis that followed in the US, Canadian public health authorities had to 
reconsider our own capacity to address similar events, recognizing the scarcity of emergency preparedness capacity in place. But more was to come. In 2003, an international outbreak of Severe Acute Respiratory Syndrome (SARS) arrived in Toronto, the largest city in the country, demonstrating directly to the population, public health authorities and political leaders the vulnerability of our health system. ${ }^{10}$ The social and economic costs were tremendous, but the impact was even greater on the confidence people had in Canada's public health systems, which were unprepared and incapable of facing such an event. ${ }^{11}$

After the SARS episode, different inquiries took place identifying in particular the lack of capacity in the public health system, the need for better communication and coordination of services, and the need for training on a large scale (graduate training and continuing education of professionals) to fill the identified gaps. ${ }^{10-13}$ This led to the creation of the Public Health Agency of Canada (PHAC) in 2005, which was a major step to develop capacity at the federal level and to meet important public health challenges. The perceived possibility of financing for public health training programs from the federal government was a significant incentive to promote the development of new educational programs and schools of public health along the lines of the US model of SPHs developed over the previous century and across the country. At the same time, in the US and also in Europe, significant developments in the domain of public health training were also taking place. In the last decade, the number of SPHs accredited by the Council on Education for Public Health (CEPH) in the US has increased from 32 to 45 , and accredited graduate programs have increased from 49 to $79^{14,15}$ with a similar expansion of the number of MPH programs across Europe.

Reflecting the renewed interest in public health in Canada, representatives from federal, provincial and territorial $(\mathrm{F} / \mathrm{P} / \mathrm{T})$ governments, as well as academic colleagues, collaborated in producing a pan-Canadian Framework for Public Health Human Resources Planning (2005), along with a set of public health core competencies that were finalized and released by PHAC in 2007. ${ }^{16,17}$ During this same time period, a new pan-Canadian Public Health Network to support intergovernmental collaboration for public health in Canada was created including, since November 2005, a dedicated pan-Canadian Public Health Human Resources Task Group. In recent years, this task group worked with the academic community to develop a 
set of $\mathrm{MPH}^{*}$ program and practicum guidelines to "support the development of MPH programs in this country with sufficient consistency and quality to meet the public health systems' needs". ${ }^{18}$

\section{EXPLOSION IN TRAINING OPPORTUNITIES IN PUBLIC HEALTH IN CANADA}

As previously mentioned, the historical status quo with respect to a small number of professional MPH programs has changed rapidly since the SARS wake up call. In the past several years, there has been an explosion of new academic programs and institutions. Three particular areas of expansion are described here: MPH programs, SPHs and undergraduate (baccalaureate) public health programs.

\section{MPH Programs}

From about five programs in the 1990's, ${ }^{19}$ as of September 2011 there will be 15 Canadian universities offering MPH-type degrees in public health, with a typical duration of one or two years (Table 1). At least three other universities are also at various planning stages for offering such programs in the near future. Most of the universities have converged to label their programs as 'MPH degrees', although universities in Québec continue to offer MSc degrees with a practicum. Nevertheless, there appears to be a common perspective that these programs provide "a professional degree whose primary purpose is to prepare students for public health practice". ${ }^{18}$

The diversity of programs is indicated by the range of areas of focus and concentration currently being offered (Table 1). Not included in the table are other graduate degree programs that may be public health-related (e.g., master's degree in health policy and equity) since it has not been assessed whether or not, or to which extent, such programs share core curriculum/ competencies with MPH programs. Obviously, such interdisciplinary programs are part of the developments in public health and strategic alliances between universities and with the public health network will help maintain focus on quality training for practitioners. ${ }^{20}$

\footnotetext{
* The acronym "MPH" includes other master's degree programs in the Canadian context (e.g., MHSc, MHA, MHSA, MHS, MSPH, and MSc) which focus on preparing individuals for public health practice in a community setting and offering practicum.
} 


\section{Table 1}

Public Health Professional Master Degree Programs in Canada, 2011

\begin{tabular}{|c|c|}
\hline University & Available Stream/Focus/Concentration* \\
\hline University of Victoria (BC) & Generalist $^{* *}$ (Planned September 2011) \\
\hline $\begin{array}{l}\text { University of British } \\
\text { Columbia (BC) }\end{array}$ & $\begin{array}{l}\text { Epidemiology and biostatistics; occupational and } \\
\text { environmental health; maternal child health; global and } \\
\text { indigenous populations; health services and policy; social and } \\
\text { life course; emerging threats; rapid response }\end{array}$ \\
\hline $\begin{array}{l}\text { Simon Fraser University } \\
\text { (BC) }\end{array}$ & $\begin{array}{l}\text { Environmental and occupational health; global health; } \\
\text { population health; social inequities and health }\end{array}$ \\
\hline University of Alberta (AB) & $\begin{array}{l}\text { Applied biostatistics; environmental and occupational health; } \\
\text { epidemiology; global health; health policy and management; } \\
\text { health promotion; public health leadership }\end{array}$ \\
\hline $\begin{array}{l}\text { University of Saskatchewan } \\
\text { (SK) }\end{array}$ & Generalist \\
\hline University of Manitoba (MB) & Generalist \\
\hline University of Waterloo (ON) & Sociobehavioural science \\
\hline University of Guelph (ON) & Generalist \\
\hline Lakehead University (ON) & Generalist; nursing \\
\hline $\begin{array}{l}\text { University of Toronto }{ }^{* * *} \\
(\mathrm{ON})\end{array}$ & $\begin{array}{l}\text { Epidemiology; community nutrition; occupational \& environ- } \\
\text { mental health; health promotion; family and community medicine }\end{array}$ \\
\hline Queen's University (ON) & Generalist \\
\hline $\begin{array}{l}\text { University of Montréal } \\
\text { (QC) }\end{array}$ & $\begin{array}{l}\text { Health promotion; occupational hygiene; health administration; } \\
\text { community health; toxicology and risk assessment }\end{array}$ \\
\hline McGill University (QC) & $\begin{array}{l}\text { Epidemiology, biostatistics, occupational health, public health } \\
\text { (Planned September 2011) }\end{array}$ \\
\hline Laval University (QC) & $\begin{array}{l}\text { Epidemiology, evaluation, health promotion, community health, } \\
\text { global health }\end{array}$ \\
\hline Memorial University (NL) & Population and public health; nutrition and dietetics \\
\hline
\end{tabular}

*As described on universities' program websites.

** 'Generalist'-type MPH degrees are described in both the CEPH accreditation criteria and the Canadian MPH Guidelines. Both state: a 'generalist MPH' offers “a course of study to provide the student with a sound academic background in order to practice competently as a generalist in public health". 18

**** Students may also pursue a 'global health focus' in addition to one of the degree specializations. **** Degrees are MSc (Community Health).

Note: additional universities are at various stages of planning to develop MPH programs (e.g., Carleton (ON); Ottawa (ON); Dalhousie (NS)). 
The expansion in availability of MPH programs has generally been welcomed by the public health community in Canada. ${ }^{18}$ However, concerns were raised regarding the potential for new programs being developed in relative isolation and with little guidance available for universities offering/ planning these programs. As a result, a set of voluntary MPH program and practicum guidelines was established in 2006/2007 involving academics from public health graduate programs and public health practitioners. ${ }^{18}$ These guidelines were heavily influenced by the CEPH accreditation criteria and the Association of Schools of Public Health in the European Region (ASPHER) PEER review criteria. ${ }^{21,22}$ Reported anecdotally, the development of at least some new MPH programs has been informed by the guidelines. In addition, when a national awards program was established by PHAC and the Canadian Institutes of Health Research (CIHR) to support students attending MPH programs, only students attending programs meeting the guidelines were eligible. A more thorough assessment of the guidelines' impact and their potential revision is planned for late 2011. Information on the descriptive characteristics of MPH programs (e.g., number of registered students, duration, credits, faculty, practicum, curriculum, etc.) is not currently available in a consistent manner. At a meeting of Canadian public health academic institutions in the fall of 2010, interest was expressed in gathering this information in 2011. An early estimate suggests that there are actually as many as 500 new graduates per year, and with expansion in the size and number of programs, this estimate is expected to increase in the future.

\section{Schools of Public Health}

The past decade has seen the re-emergence of SPHs in Canada, which had been absent since the 1970's. In recent years, several universities across Canada have established new SPHs (Table 2).

Among Canadian universities, the term 'school' is used to refer to academic units of varying size and organizational level within university structures: a department, a sector or many departments under the authority of a faculty or even an independent school. This currently also applies to Canadian SPHs. Many of the SPHs reflect the transition of longstanding public health-related departments into SPHs with different levels of autonomy within their university. There is currently considerable heterogeneity in the levels and types of degrees offered. Most of the SPHs offer master and doctoral level degrees, and many also have graduate level diplomas or certificates, although this is not universal. 
Table 2

Schools of Public Health in Canada, 2011

\begin{tabular}{l|c|c}
\hline \multicolumn{1}{c|}{ School } & University & Degrees Offered \\
\hline $\begin{array}{l}\text { School of Public Health and } \\
\text { Social Policy }\end{array}$ & University of Victoria & BAHCS*; MPH \\
\hline $\begin{array}{l}\text { School of Population and Public } \\
\text { Health }\end{array}$ & $\begin{array}{c}\text { University of British } \\
\text { Columbia }\end{array}$ & $\begin{array}{c}\text { MHA; MHSc; MPH; MSc; } \\
\mathrm{PhD}\end{array}$ \\
\hline School of Public Health & University of Alberta & MPH; MSc; PhD \\
\hline School of Public Health & University of Saskatchewan & MSc; MPH; PhD \\
\hline $\begin{array}{l}\text { School of Occupational and } \\
\text { Public Health }\end{array}$ & Ryerson University & BASc \\
\hline $\begin{array}{l}\text { Dalla Lana School of Public } \\
\text { Health }\end{array}$ & University of Toronto & MPH; MSc; MScCH; PhD \\
\hline School of Public Health & University of Montréal & MSc ${ }^{* *} \mathrm{PhD}$ \\
\hline
\end{tabular}

${ }^{*}$ BAHCS $=$ Bachelor of Arts in Health and Community Services; BASc $=$ Bachelor of Applied Science.

${ }^{* *}$ Master with thesis (research) and Master with practicum (professional), both offered.

\section{Undergraduate Programs}

An even newer development is the establishment of public health focused undergraduate degree programs.$^{23}$ Historically, many Canadian universities have had 'health sciences' undergraduate programs and some students would have subsequently pursued health professional programs such as nursing, dentistry, and medicine. At this point, a limited number of Canadian universities are offering public health focussed undergraduate degree programs (e.g., Ryerson University and Brock University in Ontario, and the University of Lethbridge in Alberta), and this is an issue being considered by other institutions. Little analysis or discussion has occurred yet regarding these programs within Canada and their relation to system needs, training paths, competencies, etc.

\section{TOWARDS A CANADIAN NETWORK OF PROGRAMS AND SCHOOLS OF PH}

Following the explosion of public health programs and schools in Canada, the notion of core curriculums for MPHs and more broadly for public health training in general has become a topic of high interest for the different 
universities. The Core Competencies and the Guidelines for MPH programs in Canada produced by the pan-Canadian Public Health Human Resources Task Group in collaboration with PHAC are considered as 'working documents' for developing individualized sets of expectations for the different programs offered. Both were written with the intent to revise them as experience was gained in their use. Standardizing curriculum is not at the forefront of priorities but is raised by different actors as a developing issue with the demand for greater professionalization in the public health sector, as we are seeing in the US, and the greater need for quality and consistency. ${ }^{24}$

An inaugural meeting of representatives from more than 20 different Canadian institutions offering or planning undergraduate and graduate programs in public health, including those with SPHs, was recently convened with the support of the Canadian Public Health Association (CPHA) and PHAC. At that meeting, the creation of an inclusive Canadian Network of Public Health Schools and Programs was actively discussed. Even though many possibilities were identified, different models discussed and no final decision made, the need for a common hub to gather the emerging strengths for public health training in Canada was prioritized. This new network would primarily focus on improving the quality of the programs, facilitate communication and collaboration between the members and promote public health training, research and capacity building activities. Greater collaboration may also lead to higher standards, reduced duplication and greater efficiency of efforts (e.g., development of web-based distance learning).

At the same meeting, the question of accreditation by independent bodies was also raised as an important issue, but likely necessitating collaborations with broader international entities already in place like CEPH or ASPHER. This question of accreditation could be quite divisive between future members of the network with the perception of a two tier system: internationally accredited programs and SPHs; and non-accredited programs and SPHs. Currently, two Canadian MPH-type programs are accredited by CEPH (Université de Montréal in Québec and Simon Fraser University in British Columbia) and three Master of Health Administration programs are accredited by the Commission on Accreditation Healthcare Management Education (Toronto, Montréal, and Dalhousie University in Halifax). CEPH has relatively prescriptive criteria for SPHs including their independence, faculty complement, and degree requirements by discipline. ${ }^{25}$ At present, only one Canadian SPH, at the University of Alberta in Edmonton, is in the process of pursuing the US CEPH-SPH accreditation. The creation of a Canadian-based system of accreditation of public health programs and schools was discussed at the fall 2010 meeting. A Canadian- 
based system is not being actively pursued at this time as we are still in the early stage of development of our network, we may not have the critical mass to support our own accreditation system, and there are other options available internationally in the US or in Europe.

Linked with the question of quality is also the issue of sustainability. There is actually no clear or quantitative evaluation of the extent of system needs for graduate training in public health in Canada. The general calls for more training options post-SARS have been met with a substantive response from academic institutions. The question of sustainability of those programs and schools may be raised at some point, but is very difficult to pinpoint precisely, recognizing that a significant proportion of the trainees are coming to Canada from all over the world - close to 50 percent in certain programs or SPHs. In addition, a number of trainees are working outside the traditional public health network, such as in clinical practice or in research. In Canada, the provision of health services and education are provincial responsibilities, as they were defined by the Confederation Act from 1867. Obviously, much has changed since then and intersectoral activities are performed at all levels. PHAC and the intergovernmental Public Health Human Resources Task Group have been very active and supportive in furthering public health workforce development in Canada. Nevertheless, much more needs to be done to support the development of these programs and each province and its universities will have to jointly collaborate in such an enterprise.

The need for continuing professional training has also come up as a great demand from public health authorities. This could be of even greater importance than the need for new graduates as professionals in place often do not have the full training necessary to fulfill the expectations of the new public health agenda for the population. In 2005, the Institut National de Santé Publique du Québec (INSPQ) made a needs assessment of public health training for front-line public health providers in the province that showed the immense demand for continuing education. Even though the majority had significant experience in public health, less than seven percent had a graduate training degree in public health or public health related discipline. Hence, two thirds of the respondents were looking for master degree level training in public health through a micro program and 95 percent of those preferred an intensive continuing education format (Céline Farley, INSPQ, personal communication, 2011). Some universities, in Ontario and Québec notably, with the close partnership of national and provincial public health agencies and regional authorities are already responding to this new and growing challenge. 


\section{CONCLUSION}

In conclusion, this article demonstrates the considerable changes in the field of public health training in Canada. Even though there is significant interest in the fields of prevention and health promotion, partly related to increasing health services' costs, the recent explosion of programs and SPHs in the country has more to do with a reaction to major health protection challenges from emerging threats, like SARS. The spinoffs could be very significant in terms of capacity development and quality improvement if universities and public health agencies work closely together with provincial/territorial and local/regional public health authorities to address the real challenges of training in our domain.

The future development of these schools and programs will be highly dependent on very close collaborations with all the actors involved. A detailed enumeration to ascertain the actual capacity of the public health system is required as is an assessment of current and future educational needs and should be major priorities in our highly decentralized system. The creation of an inclusive Canadian Network of Schools and Programs of public health is a very good step in that direction.

Acronyms list:

ASPHER $=$ The Association of Schools of Public Health in the European Region $\mathrm{CEPH}=$ The Council on Education for Public Health

PHAC $=$ The Public Health Agency of Canada

SARS $=$ Severe Acute Respiratory Syndrome

SPHs $=$ Schools of Public Health

Acknowledgements: We would like to thank John O'Neil (UBC), Harvey Skinner (York U.), and Bart Harvey (UofT) for their comments on an earlier version of this manuscript.

Conflicts of interest: None declared.

\section{REFERENCES}

1. Defries RD. Postgraduate teaching in public health in the University of Toronto, 1913-1955. Can J Public Health. 1957;48:285-94.

2. Beaton GH. Community health: a new approach in the University of Toronto. Can J Public Health. 1974;65:463-6.

3. Desrosiers G, Gaumer B, Keel O. Contribution de l'École d'Hygiène de l'Université de Montréal à un enseignement francophone de santé publique, 1946-1970. Revue d'histoire de l'Amérique française.1994;47:323-47.

4. Lalonde M. A new perspective on the health of Canadians. Minister of Supply and Services Canada: Ottawa; 1974. 
5. World Health Organization. Ottawa charter for health promotion. Geneva: WHO; 1986.

6. Tulchinsky TH et al. Proceedings of the International Conference on Developing New Schools of Public Health. Jerusalem, Israel. March 17-21, 2002. Public Health Reviews 2002;30:1-392.

7. World Health Organization. CSDH report: Closing the gap in a generation: health equity through action on the social determinants of health. Final Report of the Commission on Social Determinants of Health. Geneva: WHO; 2008.

8. The Honourable Dennis R. O'Connor. Report of the Walkerton Inquiry: The Events of May 2000 and Related Issues, 2002. Available from URL: http:// www.attorneygeneral.jus.gov.on.ca/english/about/pubs/walkerton/ (Accessed 15 May, 2011).

9. Laing RD. Report of the Commission of Inquiry into matters relating to the safety of the public drinking water in the City of North Battleford, Saskatchewan, March 28, 2002. Available from URL: www. northbattlefordwaterinquiry.ca/inquiry/inquiry.htm (Accessed 1 May, 2011).

10. National Advisory Committee on SARS and Public Health. David Naylor, Chair. Learning from SARS: renewal of public health in Canada - a report of the National Advisory Committee on SARS and Public Health. Ottawa: Health Canada; 2003.

11. Campbell A. The SARS Commission interim report: SARS and public health in Ontario. Toronto: Ontario Ministry of Health and Long-Term Care; 2004.

12. Expert Panel on SARS and Infectious Disease Control For The Public's Health. Initial report of the Ontario Expert Panel on SARS and Infectious Disease Control. Toronto: Ontario Ministry of Health and Long-Term Care; 2003.

13. Standing Senate Committee on Social Affairs, Science and Technology. Kirby MJL, LeBreton M. Reforming health protection and promotion in Canada: time to act. November 2003. Available from URL: http://www.parl.gc. ca/37/2/parlbus/commbus/senate/Com-e/SOCI-E/rep-e/repfinnov03-e.htm. (Accessed 15 May, 2011).

14. Tulchinsky TH, Bickford MJ. Are schools of public health needed to address public health workforce development in Canada for the 21st century? Canadian Journal of Public Health. Revue Canadienne de Sante Publique. 2006;97:248-50.

15. Council on Education for Public Health (CEPH). Schools of public health and public health programs accredited by the Council on Education for Public Health. Last updated 3 December, 2010. Available from URL: http://www. ceph.org/pdf/Master_List.pdf (Accessed 1 May, 2011).

16. The Joint Task Group on Public Health Human Resources. Advisory Committee on Health Delivery and Human Services. Advisory Committee on Population Health and Health Security. Building the public health workforce for the 21st century. A pan-Canadian framework for public health human resources planning. Ottawa: Public Health Agency of Canada; 2005. Available from URL: http://www.phac-aspc.gc.ca/php-psp/pdf/building_the_public_health_ workforce_fo_\%20the-21stc_e.pdf (Accessed 1 May, 2011). 
17. Public Health Agency of Canada. Core competencies for public health in Canada. Release 1.0. Ottawa: PHAC; 2007.

18. MPH Guidelines Working Group. Guidelines for MPH Programs in Canada. Public Health Network Council - Public Health Human Resources Task Group. 2006.

19. Spasoff R. A pan-Canadian Strategy For Public Health Workforce Education 2005. Pan-Canadian Public Health Human Resources Committee (PPHHRC). Draft 5: 5 October, 2005. p. 55. Available from URL: http://www.phac-aspc. gc.ca/php-psp/pdf/pan_canadian_strategy_for_public_health_workforce_ education_e.pdf (Accessed 1 May, 2011).

20. Moloughney BW, Skinner HA. Rethinking schools of public health: a strategic alliance model. Can J Public Health. 2006;97:251-4.

21. Council on Education for Public Health. Accreditation criteria: public health programs. Amended June 2005. Washington, DC..

22. Association of Schools of Public Health in the European Region (ASPHER). Criteria for the Public Health Education European Review. 2001.

23. Johnson I, Donovan D, Parboosingh J. Steps to improve the teaching of public health to undergraduate medical students in Canada. Acad Med. 2008;83:414-8.

24. Mowat DL, Moloughney BW. Developing the public health workforce in Canada: a summary of regional workshops on workforce education and training. Can J Public Health. 2004;95:186-7.

25. Council on Education for Public Health (CEPH). Accreditation Criteria Schools of Public Health. 2005. Available from URL: http://ceph.org/pdf/ SPH-Criteria.pdf (Accessed 1 May, 2011). 